\title{
A fala ecolálica na perspectiva benvenistiana da enunciação
}

\author{
Echolalic speech from benvenistian enunciation perspective
}

\begin{abstract}
Carla Regina Murad* Juliana Vilela Alves**

Resumo: O objetivo deste artigo é problematizar o conceito de ecolalia como "patologia da fala" por meio do questionamento de alguns conceitos tradicionais do senso comum que vigoram em nossa sociedade sobre língua, fala e sujeito. A teoria da enunciação de Èmile Benveniste (2005) propõe um olhar diferente sobre a língua e a fala que, por sua vez, gera implicações tanto de cunho individual, para o falante, como social, para aqueles com quem o falante convive. A presente análise da fala de uma criança de três anos com diagnóstico de ecolalia foi baseada no Aparelho Formal da Enunciação (BENVENISTE, 2006) que, aliada aos estudos linguísticos que compreendem tal patologia como um sintoma da linguagem (FLORES, 2007), tornam o sujeito "único e irredutível" (NORMAND, 1996).

Palavras-chave: Linguística; Enunciação; Fala; Ecolalia.

Abstract: This work aims at questioning the concept of echolalia as a "speech pathology", through the mobilization of common and traditional senses that emerge in our society concerning language, speech and subject. The enunciation theory of Ėmile Benveniste offers a different approach towards speech and language with implications not only for the child as an individual but also for others with whom he/she lives. The present analysis of a three-year-old child's speech with a diagnosis of "echolalia" was based on the Formal Apparatus of Enunciation (BENVENISTE, 2006) together with linguistic studies which defines such pathology as a language symptom (FLORES, 2007), revealing a "unique and irreducible" individual. (NORMAND, 1996).
\end{abstract}

Keywords: Linguistics; Enunciation; Speech; Echolalia.

\section{Introdução}

"[...]o ato de fala parte de mim e ninguém pode falar por minha boca, da mesma forma que não pode ver por meus olhos ou experimentar o que eu sinto[...]."

(BENVENISTE, 2006, p.77)

A ecolalia é comumente entendida como sendo uma repetição ou cópia que uma pessoa faz de frases outras vindas de seus interlocutores. A fala repetitiva, então, soaria como um "eco", e o indivíduo como um papagaio, um ser desprovido de espontaneidade, identidade ou autoria. A patologia é comumente considerada um distúrbio de linguagem a ser extirpado da fala e tem sido considerada evidência de uma limitação de entendimento do falante quando comparada ao desempenho linguístico normal ou ao falar correto.

\footnotetext{
* Doutoranda do Programa de Pós-Graduação em Estudos Linguísticos da Universidade Federal de Uberlândia e bolsista CAPES.

** Mestre em Linguística Aplicada pela Universidade Federal de Uberlândia e docente no IFTM-Uberlândia.
} 
$\mathrm{Na}$ perspectiva teórica benvenistiana da enunciação, não existiria erro na fala e a comunicação não passaria de uma consequência da mesma. O falar diferente, fruto da subjetividade de um indivíduo, seria uma projeção de sua singularidade, pois a linguagem é o próprio lugar da subjetividade, o que define o homem. Ela possibilita ao locutor se apresentar ao seu interlocutor como sujeito da linguagem e, assim, por meio da intersubjetividade, têm a oportunidade de se significarem.

Este artigo está dividido em três partes. Na primeira, procuramos demonstrar como Benveniste problematiza alguns conceitos linguísticos até hoje arraigados em nossa sociedade e a implicação dos mesmos para noções que fundamentam as perspectivas epistemológicas de seu trabalho. Na segunda, buscamos fundamentar nossa análise, introduzindo os principais elementos da teoria da enunciação de Benveniste. Na terceira e última parte, analisamos as irregularidades linguísticas de $\mathrm{C}$, uma criança de três anos com diagnóstico de "distúrbio da fala/ecolalia", a partir da abordagem enunciativa da linguagem.

\section{Principais conceitos e implicações da teoria da enunciação de Benveniste}

No capítulo 21 da parte V de "Problemas de Linguística Geral I", intitulado "Da subjetividade na linguagem" (2006, p. 284), Benveniste problematiza dois conceitos amplamente difundidos na sociedade. O primeiro é a concepção de língua como instrumento de comunicação. Segundo o autor, instrumentalizar a língua implica em adotar uma "noção simplista a respeito da linguagem" cujas razões são um tanto confusas. A primeira porque "os homens não encontraram um meio melhor nem mesmo tão eficaz para comunicarem-se", sendo a língua então tomada pelo ou equivalente a um instrumento. $E$ a segunda é porque a linguagem apresenta "disposições que a tornam apta a servir de instrumento", produzindo a ilusória noção de transmissão. Na verdade, pode-se depreender que o princípio que governaria a comunicação tal como é concebida pela nossa sociedade seria o da transmissibilidade, ou seja, a propriedade de transmitir algo a alguém, o que é um pouco diferente de transmissão, que sugere um afastamento entre homem, que estaria na origem do processo, e língua, oportunizando a falsa impressão de que a língua é um objeto separado do homem. Em suas palavras:

Falar de instrumento é pôr em oposição o homem e a natureza. A picareta, a flecha, a roda não estão na natureza. São fabricações. A linguagem está na natureza do homem, que não a fabricou. Inclinamo-nos sempre para a imaginação ingênua de um período original, em que um homem completo 
descobriria um semelhante igualmente completo e, entre eles, pouco a pouco, se elaboraria a linguagem. Isso é pura ficção. (BENVENISTE, 2006, p. 285)

Uma outra crença que Benveniste desmistifica é a possibilidade de se pensar em uma origem da linguagem ou que existiriam línguas primitivas ou formas de comunicação primitivas como os desenhos das cavernas que evoluíram para formas de comunicação mais complexas como a língua. A concepção de 'evolução linguística' é que estaria sendo questionada aqui.

É na noção de língua enquanto sistema de signos linguísticos que todo o aparato teórico de Benveniste se sustenta (2006, p. 224). A forte influência de Saussure, seu precursor nos estudos sobre a língua, pode ser vislumbrada na fundamentação de sua teoria de duas maneiras. A primeira passa pelo entendimento de que língua é sistema e não conjunto de elementos, ou estrutura, fato que gera implicações, tal como a de que não há uma essência na língua a ponto de ser possível entender a existência humana separada da linguagem. A assertividade de Benveniste esclarece:

Não atingimos nunca o homem separado da linguagem e não o vemos nunca inventando-a.[...]É um homem falando que encontramos no mundo, um homem falando com outro homem, e a linguagem ensina a própria definição do homem. (idem, ibidem)

Ao se organizarem na inter-relação entre si, por oposição uns aos outros, ou diferença e negação, um signo é o que o outro não é, ou seja, ele ocupa uma posição convencionada; os signos, cada um deles estruturado em significado e significante, constituem um sistema pelo princípio da arbitrariedade. Benveniste explica que considerar o signo encerrado em si mesmo, "como portador de um valor" (p.58), é o mesmo que eliminar a arbitrariedade, pois o conceito sugere relação entre dois ou mais signos. $\mathrm{O}$ valor deve ser entendido como "um atributo da forma, não da substância". Portanto, a relação deve existir entre um signo e outro e não entre as partes, significado e significante, que compõem o signo. Em suas palavras: "É no uso da língua que um signo tem existência; o que não é usado não é signo; e fora do uso o signo não existe.” Não há estágio intermediário; ou está na língua ou está fora da língua, “tertium non datur”. (idem, p. 227).

O segundo conceito, também arraigado em nossa sociedade, é uma implicação do primeiro e diz respeito à relação do homem com a língua. Em ambas as citações anteriores, Benveniste coloca a língua como parte do homem, de sua natureza, e não fora, ou a priori dele. Apesar de o movimento de ir e vir das palavras sugerir uma troca, nada justifica acreditar que 
o homem tem o poder de emitir e captar uma mensagem que foi transmitida ou comunicada. Observamos o quanto estamos sujeitos à língua quando falamos "não foi isso que eu quis dizer" ou "você não me entendeu". Como bem disse Saussure, "o homem não é o senhor da língua" (2006). Portanto, a refutação do caráter externo da linguagem em relação ao homem, o que equivaleria dizer que língua é um objeto e como tal, pode-se medir a capacidade cognitiva de um homem pelo seu desempenho, sua fala, é essencial para o estabelecimento de um marco conceitual para o entendimento da proposta enunciativa de linguagem benvenistiana.

Essa sujeição à língua que é sistêmica produz efeitos no homem. Ao mesmo caberia uma posição ou lugar na língua, que Benveniste denominou de "subjetividade", a uma capacidade do locutor de se propor como sujeito. Ela é definida não pela experiência de ser, mas pela garantia da consciência. Benveniste não utiliza o termo/'sujeito da enunciação' ou 'sujeito do inconsciente'. A palavra 'sujeito' aparece na seguinte frase: 'É na linguagem e pela linguagem que o homem se constitui como sujeito: porque só a linguagem fundamenta a realidade, na sua realidade, que é a do ser, o conceito de "ego'." (BENVENISTE, 2006, p.286) É o "ego" que enuncia. No entanto, para saber-se consciente é preciso de algum contraste, criado por uma condição de diálogo. A partir da noção de polaridade de pessoas na linguagem, ou posições, como as categorias pronominais vazias, ou seja, desprovidas de significado até serem empregadas, como as formas pronominais "eu" e "tu", Benveniste conclui que a comunicação é consequência pragmática da ocupação desses lugares, dessas posições, das quais precisamos para nos apresentar, para o nosso ser emergir, para que possamos ser singulares, únicos. A noção de polaridade é única e inerente à linguagem. Não há nada semelhante na natureza. Como bem diz Benveniste:

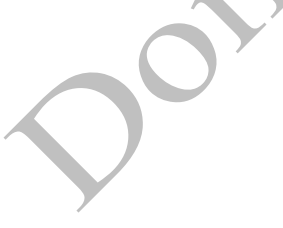

Essa polaridade não significa igualdade nem simetria: ego tem sempre uma posição de transcendência quanto a tu; apesar disso, nenhum dos dois termos se concebe sem o outro; são complementares, mas segundo uma oposição "interior/exterior, e ao mesmo tempo são reversíveis. Procure-se um paralelo para isso; não se encontrará nenhum. Única é a condição do homem na linguagem. (BENVENISTE, 2006, p. 286)

Há que se esclarecer que a complementaridade é dada pelas posições, ora de ouvinte ou locutário ou no exterior, ora de falante, ou locutor ou no interior do processo do ato de falar, que podem se alternar indefinidamente, ao se movimentarem nessas posições. Novamente, o diálogo assume o papel si ne qua non de condicionante da entrada ou emergência do sujeito na linguagem.

(C) Carla Regina Murad, Juliana Vilela Alves 


\section{A teoria: o Aparelho Formal da Enunciação}

Um dos princípios que norteiam os estudos da Enunciação de Benveniste é o de considerar a língua em uso, ou seja, em funcionamento, surgindo daí a noção de enunciação como "colocar em funcionamento a língua por um ato individual de utilização" (2006, p.82). Em seu texto A forma e o sentido na linguagem, ele afirma que "a linguagem significa" ( $p$. 222), sendo essa a sua "vocação original" e bem antes de servir para comunicar, "a linguagem serve para viver". É ela que possibilita a existência da sociedade e da humanidade.

Nesse texto, Benveniste fala aos filósofos sobre a noção de semântica e a sua expressão na língua por meio de frases. Segundo o autor:

A noção de semântica nos introduz no domínio da língua em emprego e em ação; vemos desta vez na língua sua função mediadora entre o homem e o homem, entre o homem e o mundo, entre o espírito e as coisas, transmitindo a informação, comunicando a experiêneia, impondo a adesão, suscitando a resposta, implorando, constrangendo; em resumo, organizando toda a vida dos homens. [...] Somente o funcionamento semântico da língua permite a integração da sociedade e a adequação ao mundo, e por consequência a normalização do pensamento e o desenvolvimento da consciência. (BENVENISTE, 2006, p.229)

No Aparelho formal da enunciação, Benveniste propõe um quadro geral de possibilidades a serem investigadas pela teoria da enunciação, cujo objetivo seria o estudo das organizações linguísticas em uso, em situações dialógicas específicas em que estão significando. Ele inicia o capítulo distinguindo o emprego das formas do emprego da língua para poder propor o conceito de enunciação. Segundo ele, "enunciação é este colocar em funcionamento a língua por um ato individual de utilização” (p. 82). Em seguida, ele esclarece que a fala é o lugar onde se deve buscar o sentido, a partir das marcas do sujeito das formas, ou seja, sempre dentro dos limites e das possibilidades do sistema linguístico e na perspectiva relacional.

São três os aspectos por meio dos quais se pode estudar o processo da enunciação: 1) o fenômeno da realização vocal da língua nas diversas situações enunciativas, ou seja, as vocalizações individualizadas, 2) o fenômeno da semantização, isto é, como o sentido se forma em palavras e 3) os instrumentos de sua realização.

Segundo Benveniste, a enunciação pode ser definida em relação à língua como um processo de apropriação (p. 84). Em suas palavras, "o locutor se apropria do aparelho formal 
da língua e enuncia sua posição de locutor por meio de índices específicos, de um lado, e por meio de procedimentos acessórios, de outro.” (idem) Segundo Normand:

Sua função é a de tornar possível a significação, atualizando nas frases diferenças formais que, de outro modo, ficariam vazias; mas essa função está ligada a um ato de apropriação que nunca tem um ponto fixo, já que ele é próprio de um sujeito inatingível, cada vez mais único e irredutível. (NORMAND, 1996, p.149)

Em outras palavras, as marcas que devem ser buscadas na língua são as formas linguísticas, ou seja, os pronomes, as flexões verbais, os advérbios é o que deveser o ponto de partida para se buscar como o sujeito se propõe como ser de linguagem.

Toda enunciação é uma alocução, pois ao se declarar locutor imediatamente se “implanta o outro diante de si” (BENVENISTE, 2006, p. 84), denominado de alocutário, a condição dessa apropriação da língua é a necessidade do locutor de referir pelo discurso, ao passo que para o outro, o alocutário, é a possibilidade de "correferir identicamente no consenso pragmático que faz de cada locutor um colocutor". Estes são os pré-requisitos ou as condições iniciais para o que se denomina de "encaixe" ou "efeito pragmático" entre interlocutores.

Segundo Benveniste, desde o momento em que o enunciador se serve da língua para influenciar o comportamento do alocutário, ele dispõe de um aparelho de funções: a interrogação, cuja enunciação é construída para suscitar uma "resposta", "por um processo linguístico que é ao mesmo tempo um processo de comportamento com dupla entrada" (p. 86), isto é, dupla entrada no sistema linguístico, como falante que enuncia e ouvinte que escuta sua própria interrogação. A intimação ou ordens, apelos provenientes dos imperativos e vocativos, “implicam um relação viva e imediata do enunciador ao outro". A asserção, que visa "comunicar uma certeza", é a "manifestação mais comum da presença do locutor da enunciação". Por fim, nessa categoria organizam-se todos os tipos de modalidades formais pertencentes aos verbos, como os modos e as fraseologias.

Benveniste afirma que a "acentuação da relação discursiva com o parceiro, real ou imaginado, individual ou coletivo é o que caracteriza a enunciação" (p.87). Essa característica é denominada de "quadro figurativo da enunciação" ao colocar duas "figuras" ou "protagonistas", uma representando a origem e a outra o fim da enunciação, alternadamente, formando, assim, a estrutura do diálogo. O monólogo é considerado uma "variedade do 
diálogo", "um diálogo interiorizado, formulado em linguagem interior entre um eu locutor e um eu ouvinte" (p. 87).

Outra prática comunicativa a ser analisada é a "comunhão fática", isto é, processo em que o discurso, sob a forma de um diálogo, estabelece uma colaboração entre os indivíduos para preencher uma função social, seu principal objetivo: perguntas sobre saúde e comentários sobre o tempo são trocadas não com a finalidade de informar ou expressar pensamentos ou ainda refletir, seja intelectualmente ou não, sobre algo que foi dito.

Em suma, Benveniste deixa em aberto as várias possibilidades de desdobramentos que deveriam ser analisadas na perspectiva enunciativa. O objetivo da nossa análise é justamente colocar em xeque a posição tradicional que $\mathrm{C}$ ocuparia em relação à língua, na perspectiva da enunciação de Benveniste, explorando, por meio das marcas linguísticas que C deixa na língua ao se subjetivar, em situações dialógicas com a sua mãe.

\section{Metodologia e análise}

Após uma breve descrição de $\mathrm{C}$, sobre a qual foi realizada a análise, utilizaremos as categorias propostas por Benveniste para como ponto de partida para uma breve análise de sua fala.

C é uma menina de três anos que iniciou a fala, de fato, após uma cirurgia que ocorreu ao completar dois anos; uma laparoscopia de correção da válvula esofágica para estancar o frequente refluxo. No período anterior ao procedimento cirúrgico, no entanto, há registro apenas de comportamentos e atividades fisiológicas como balbucios, risos e choros feitos pela mãe de C. Nada de muito significativo linguisticamente havia sido ainda produzido. O contato visual com $\mathrm{C}$ também era problemático antes da cirurgia. À medida que $\mathrm{C}$ se recuperava das consequências do refluxo, sua linguagem também apresentava mudanças. Hoje, a fala de C é definida por neurologistas como "atrasada".

$\mathrm{O}$ corpus retrata a situação linguística atual de $\mathrm{C}$, à época do registro dos dados com exatos três anos e dez meses. Foram selecionados trechos com pequenos diálogos e uma cena noturna em que $\mathrm{C}$ consegue produzir uma "conversa" mais longa do que de costume com sua mãe. A fala de $\mathrm{C}$ é permeada de formas exclusivas de endereçamento. Procuramos manter a fidelidade ao reproduzir as falas de C, para que elas pudessem ser escrutinadas a contento. Analisaremos as seguintes instanciações: produções fônicas, interrogações, monólogos e diálogos. 


\section{Enunciações fônicas}

Observando os segmentos abaixo, nota-se que há, na enunciação, uma modificação fonêmica que torna a fala de $\mathrm{C}$ em relação à fala da irmã um pouco diferente, colocando em cheque a afirmação de que a fala de C é ecolálica. Em (1), durante brincadeira de apostar corrida com a irmã, pelo acréscimo do fonema /r/ e supressão do /u/ em 'vou', ocasionando uma elisão que torna o enunciado singular, e não repetitivo, se levarmos em conta que o contexto permitia uma repetição: o grito de largada de ambas. No entanto, a subjetividade de C emerge na cadeia linguística, na posição “eu”, de locutora.
A (irmã): "Lá vou eu! “
B ( C ): "Lá vorreu!"

Outros exemplos podem ser observados das falas já apropriadas que ouviu da mãe, dos colegas da escola, da professora, irmã, enfim, todos os 'outros' que a constituem. No entanto, eles trazem evidências de singularidade, pois $\mathrm{C}$ imprime sua própria marca ao pronunciar com diferença as palavras que a estão constituindo, o que afastaria a concepção da existência de um ser ecolálico, repetitivo. As formas observadas neste corpus foram: "titi" - "assistir", "Jub Jub" - "Jup Jup" (personagem), "chá' - “já" e "gustoso" - "gostoso".

\section{Enunciações com dupla entrada: interrogações e monólogos}

\section{Interrogações}
(Dirigindo-se à gaveta de DVDs)
$\mathrm{C}$ : "Ce qué titi Jub Jub?
C: "-Não."
C: "Ce qué titi Hello Kitty?"
C: " - Não."
C: "Ce qué Babar?
C: "-Não."

(Dirige-se ao armário da cozinha e pega o suco)

C: "Cê qué suco?"

(Aproximando-se do fogão, próximo à mãe)

C: "Cê tá com fome?" 
Essa seleção de interrogativas que podem parecer "repetições' ou “ecos” da fala da mãe é a forma com que usa literalmente a dupla entrada na língua para pedir algo. Na primeira fala, ela pergunta se a mãe quer assistir algum desses DVDs. Mas, na verdade, é ela quem se dirige à gaveta de DVDs, pega o DVD que a interessa e liga o aparelho e a TV. Nessa situação, temse implicitamente: "Eu não quero assistir Jup Jup, nem Hello Kitty e nem Babar. Vou procurar outra coisa na gaveta." No caso de oferecer suco, acontece da mesma forma. Ela oferece o suco e vai até o armário da cozinha pegar a caixinha do suco. Subentende-se: "Eu quero suco." Do mesmo modo acontece com a terceira pergunta. Ao perguntar se estou com fome, senta-se na mesa e aguarda o jantar ficar pronto e ser servido. Aqui, similarmente ao exemplo anterior, pode-se inferir "Estou com fome”. Pode-se pensar que houve aqui uma inversão de polaridades, em que "tu” significa “eu”. Mas, pode-se entender também que a pergunta serve ao alocutário assim como ao locutor, ou seja, o endereçamento ocorreu simultaneamente entre as posições, ocasionando um ‘curto circuito’ no sistema dialógico.

\section{Monólogos}

Ao acordar, C enuncia: "Hi-five volta já!”, com entonação e a voz mais afinada, e uma leve mudança no fonema /j/ (volta “chá"). Hi-five é um programa infantil do Canal Discovery Kids. Os apresentadores dos programas geralmente não aparecem, mas pode-se reconhecer, pelas suas vozes, que são crianças. Ao enunciar essa frase, $\mathrm{C}$ parece estar preenchendo as duas posições "eu" e "tu" ao mesmo tempo.

Um outro exemplo evidencia a dupla entrada de $\mathrm{C}$ no sistema. Ao enunciar as falas da professora e dos colegas em “A: Quem qué casar com o Bruno? A: -Eu! Quem qué bolo gustoso? A: -Eu! Quem qué brigadero de morango? A: Eu!", ocupa, as duas posições ao mesmo tempo, ou seja, a de locutora e alocutária, evitando ou resistindo ao diálogo, por meio do monólogo.

\section{Enunciações com comunhão fática: diálogos}

Os próximos trechos são evidências de que o diálogo produziu o encaixe ou efeito pragmático esperado pelo alocutário, cumprindo uma função social, possibilitado pela mobilização das posições no jogo da linguagem por meio da intersubjetividade:

Se aproximando da porta da cozinha onde a mãe estava cozinhando: “Humm! Que 
cheirinho de omelete!"

No banheiro, após ter evacuado, olha para a mãe e diz: "Cocô sozinha!"

$\mathrm{O}$ fato de $\mathrm{C}$ ter tomado a iniciativa espontaneamente para se endereçar à mãe, como no primeiro exemplo, ou seja, em uma situação específica, não condiz com o diagnóstico de ecolalia pura, mas uma ecolalia funcional, isto é, em que as repetições funcionam comunicativamente. $\mathrm{C}$ se subjetiva, pois se infere pela sua exclamação, que ela "gosta" de omelete. Sua fala surtiu o efeito pragmático da comunicação, ou, cumpriu sua função social, porque não despertou uma reflexão intelectual ou qualquer tipo de reflexão no ouvinte. De forma semelhante, no segundo exemplo, $\mathrm{C}$, através da atualização do adjetivo na forma paradigmática do feminino, emerge na cadeia linguística e se subjetiya, novamente cumprindo a função social de estar agindo corretamente, como se espera de uma criança que está aprendendo as regras sociais próprias dessa faixa etária.

\section{Enunciações com endereçamento e encaixe}

Apontando para o céu:

C:"arco iris"...

Mãe: "Arco íris? Não tem arco-íris."

C: "Qué vê arco-iris!" (quase inaudível)

Com um chinelo só no pé:

C: "Cadê o chinelo da Hello Kitty?"

Mãe: "Não sei. Vamos procurar?"

C: Dá a mão para a mãe.

No primeiro exemplo, a atualização da forma "quero" ou "qué" evidencia a emergência de C como sujeito da linguagem, pois apesar da ausência pronominal, ela usa a flexão do verbo denotando o indivíduo que profere a enunciação, a autoria do enunciado. No segundo, através da interrogativa, $\mathrm{C}$ convoca a participação da mãe na busca pelo chinelo, cumprindo a função persuasiva das interrogativas, que é o de influenciar o comportamento do alocutário, tornandoo um colocutor, dando-lhe a "possibilidade de correferir identicamente." (BENVENISTE, 2006, p. 84) 


\section{Considerações Finais}

A teoria da enunciação de Benveniste oferece hipóteses que se diferem das hipóteses tradicionais sobre língua e o falante porque coloca este último no centro do processo de apropriação da linguagem. Com isso, o fenômeno da "ecolalia" pode resultar possibilidades diferentes sobre o ser enunciado ao ser observado na relação dialógica com o outro, fazendo-o transmutar de papagaio repetitivo e chegar ao status de ser único e irrepetível, singular na relação constitutiva com a linguagem.

Se a ecolalia for considerada uma patologia ou um distúrbio da fala, provavelmente não serão muitas as possibilidades de um ser "avançar" na observância da apropriação da linguagem pelo sujeito. No entanto, se a ecolalia for aceita como um sintoma de que algo, um fenômeno está ocorrendo por meio da linguagem, ela pode vir a ser uma porta de entrada para análises linguísticas que levam em conta um contexto mais amplo como a situação da produção, a história e o processo percorrido pelo sujeito em sua trajetória com os outros que o estão constituindo.

Vimos que, na perspectiva enunciativa, pode-se rastrear como se configura o sistema linguístico por meio da irrepetibilidade enunciativa de um indivíduo, através das marcas singulares que ele deixa emergir na discursividade, possibilitando, assim, vislumbrarmos uma posição diferente, única ao sujeito dito "ecolálico" que, ao ser repreendido, pode se fechar ainda mais às oportunidades de subjetivação, de participação e interação em diálogos e de intersubjetividade, condições únicas para a sua visibilidade como indivíduo.

\section{Referências}

BENVENISTE, É. Problemas de Linguística Geral I. 5. ed. Tradução de Maria da Glória Novak et al. Campinas: Ed. Pontes, 2005.

Problemas de Linguística Geral II. 2. ed. Tradução de Eduardo Guimarães et al. Campinas: Ed. Pontes, 2006. $2^{\mathrm{a}} \mathrm{ed}$.

FLORES, V. Benveniste e sintoma de linguagem: a enunciação do homem na língua. Programa de Pós-Graduação em Letras. PPGL/UFSM. 2007. Acesso em agosto de 2011. http://w3.ufsm.br/revistaletras/artigos_r33/revista33_7.pdf

NORMAND, C. Os Termos da Enunciação em Benveniste. In: O Falar da Linguagem (orgs. Sérgio Lopes Oliveira, Erika Maria Parlato e Silvana Rabello). São Paulo: Lovise. 1996. Série Linguagem. P. $129-131$. 
SAUSSURE, F. Curso de Linguística Geral. São Paulo: Cultrix. 2006.

Artigo recebido em: 19.01.2013

Artigo aprovado em: 13.04.2013 